\title{
Analysis of Hyperhomocysteinemia and Related Factors : A Case - Control Study in Northeast China
}

\section{Ding Ding}

Shengjing Hospital of China Medical University

\section{Ya Lin Zhang}

Shengjing Hospital of China Medical University

\section{Jing Xin Yang}

Shengjing Hospital of China Medical University

Yu Fu

Shengjing Hospital of China Medical University

\section{Ning Liu}

Shengjing Hospital of China Medical University

Wan Yi Lu

Shengjing Hospital of China Medical University

Yi Ming Pan

Shengjing Hospital of China Medical University

Jia Qi Guo

Shengjing Hospital of China Medical University

Hui Zhang

Shengjing Hospital of China Medical University

\section{Yan Lou}

China Medical University

Juan Kong ( $\boldsymbol{\sim}$ kongj@cmu.edu.cn )

Shengjing Hospital of China Medical University

\section{Research}

Keywords: Homocysteine, Hyperhomocysteinemia, Vitamin

Posted Date: October 15th, 2021

DOl: https://doi.org/10.21203/rs.3.rs-965130/v1

License: (a) (i) This work is licensed under a Creative Commons Attribution 4.0 International License. Read Full License 


\section{Abstract}

Objectives. Hyperhomocysteinemia (HHcy) is an easily neglected disease, which can be hidden in the body for many years without signs or symptoms. We want to explore the causes of HHcy, the correlation of HHcy with micronutrients, lifestyle, dietary habits and HHcy related genes, preventing the occurrence of HHcy.

Methods. 800 subjects (M/F, 403/397) were divided into normal Hcy and HHcy group according to the plasma levels of Hcy, compared essential characteristics by questionnaires, genetic polymorphism tested by Realtime PCR and micronutrients detected by mass spectrometry. The statistical analysis methods were Chi square tests, ANOVA, logistic regression. This trial has been registered with the trial number ChiCTR1900025136.

Results. $42.66 \%$ of $143 \mathrm{HHcy}$ cases were aged from 10 to 18 , with higher levels of zinc (Zn), vitamin A, Uric acid $(\mathrm{P}<0.05)$ and a lower level of $25-\mathrm{OH}-\mathrm{D} 3, \mathrm{VB12}$, folic acid $(\mathrm{Fol})(\mathrm{P}<0.05)$ compared to the normal group. The multivariate logistic regression significantly predicted HHcy development containing higher level of Zinc $(\operatorname{Exp}(B)=1.042 ; 95 \% \mathrm{Cl}, 1.000$ - 1.086), higher Uric $(\operatorname{Exp}(B)=1.014 ; 95 \% \mathrm{Cl}, 1.008-1.019)$, lower $B 12(\operatorname{Exp}(B)$ $=0.993 ; 95 \% \mathrm{Cl}, 0.989-0.997)$, lower Folic acid $(\operatorname{Exp}(B)=0.772 ; 95 \% \mathrm{Cl}, 0.657-0.907)$, and polymorphism of MTHFR C677T $(\operatorname{Exp}(B)=2.923 ; 95 \% \mathrm{Cl}, 1.399-6.107)$.

Conclusion. Pay more attention to those students who were facing great pressure because they are very likely to be potential HHcy patients with high levels of uric acid and zinc and anxiety.

\section{Introduction}

Homocysteine (Hcy) is a sulfur-containing amino acid, which is the intermediate metabolite of methionine and cysteine, mainly through remethylation and sulfuration ${ }^{(1)}$. In the physiological state, Hcy level in body is maintained at $5-15 \mathrm{umol} / \mathrm{L}^{(2)}$. Many factors, for instance heredity, medicine, diseases and living habits may lead to the level of Hcy exceeding the normal level, which is called hyperhomocysteinemia (HHcy) ${ }^{(3)}$. HHcy is considered a cytotoxic factor, associated with a variety of diseases, such as coronary heart disease, stroke, Alzheimer's disease, peripheral vascular disease, cancer, diabetes and osteoporosis etc $(4 ; 5 ; 6)$.

Hcy can be methylated twice by two different pathways of remethylation process. The one is methylenetetrahydrofolate reductase (MTHFR) which reduces 5,10-MTHF to form 5-methyltetrahydrofolate (5-MTHF) ${ }^{(7)}$. Then, 5-MTHF assisted by the essential cofactor of vitamin B12 adds a methyl group to Hcy composing methionine again, which requires key enzymes methionine synthase reductase (MTRR) ${ }^{(8 ; 9)}$.

Previous studies have shown that there are more than 40 sites of polymorphism in MTHFR ${ }^{(10)}$, of which C677T and $\mathrm{A} 1298 \mathrm{C}$ are the most important ${ }^{(11)}$. Compared with 677CC genotype, 677TT genotype performances about $34 \%$ MTHFR activity, while heterozygote 677 CT shows about $65 \%$ MTHFR activity ${ }^{(12)}$. The most important polymorphism of the MTRR gene is A66G ${ }^{(13)}$, which can regulate the level of Hcy by causing DNA hypomethylation ${ }^{(14)}$. Many studies have revealed that polymorphism were different in distinct geographical areas and ethnic populations $(15 ; 16 ; 17)$. 
The disorder of Hcy metabolism can cause the imbalance of biological amine transmitters in the central nervous system and then affect the learning, cognition and thinking ${ }^{(18 ; 19)}$. Therefore, the level of Hcy in blood has important clinical significance in people with different age and stress, which has been paid special attention in this study.

Folic acid is a water-soluble B vitamin involved in nucleic acid synthesis, DNA methylation and repairment,

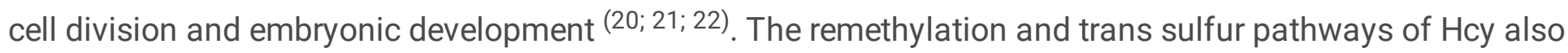
require vitamin B12 and vitamin B6 as coenzymes, respectively. Meanwhile, a two-month randomized, double-blind study found that vitamin $D$ supplementation associated with a morbidity decrease of hypertension accompanied by the reduction of Hcy level ${ }^{(23)}$. Since many vitamins play an important role in the metabolism of Hcy, in this study, the relationship between HHcy and vitamin levels were studied.

Micronutrients have a great influence on the occurrence of many diseases, among which zinc (24), iron (25) and manganese ${ }^{(26)}$ were related to atherosclerosis and vasospasm ${ }^{(27)}$. Micronutrients also involved in the complex physiological reactions of body, which serve as the components of some metabolic enzymes, or as the auxiliary factors regulating the activity of enzymes. For instance, zinc participates in more than 100 enzymes ${ }^{(27 ; 28)}$. However, there were few studies on whether micronutrients are the relevant factors influencing Hcy metabolic enzymes.

In short, the distribution characteristics of Hcy were described, and the influencing factors including micronutrients, lifestyle, diet, exercise, sleep, mood and family history were analyzed. The relationship between plasma Hcy level and gene variation of MTHFR and MTRR was discussed.

\section{Materials And Methods}

\subsection{Subjects}

From June 2019 to December 2019, according to inclusion and exclusion criteria, total of 800 subjects were collected in clinical nutrition department of Shengjing Hospital of China Medical University in shenyang. All subjects were tested with $\mathrm{Hcy}$, and divided into normal group and HHcy group according to whether their blood Hcy were greater than $15 \mathrm{umol} / \mathrm{L}$ or not.(Figure1).

\subsection{Experimental instruments and reagents}

Nucleic acid extraction reagent (TRANS, EE201-01), human MTHFR gene detection kit (Wuhan youzhiyou medical technology co. LTD) have been used commercially. PCR amplification device were 7500-fast (ABI,USA).

\subsection{Sample collection and DNA preparation}

The exfoliated cells were collected with disposable oral swabs, then DNA was extracted with DNA extraction kit and were stored at $-20^{\circ} \mathrm{C}$.

\subsection{MTHFR Genotyping}


The PCR amplification condition was $37^{\circ} \mathrm{C}$ for $10 \mathrm{~min} ; 95^{\circ} \mathrm{C}$ for $5 \mathrm{~min} ; 95^{\circ} \mathrm{C}$ for $15 \mathrm{~s}\left(40\right.$ cycles), $60^{\circ} \mathrm{C}$ for $60 \mathrm{~s}$. The fluorescence channel settings were FAM, VIC and ROX, respectively. According to the comparison of the two fluorescence signal intensities, the genotype was determined as wild type, heterozygote or homozygous mutation. (Figure2).

\subsection{Statistics}

Statistical software of SPSS 20 (IBM Corp., Armonk, NY, USA) was used for data processing and statistical analysis. The HardyWeinberg balance test was used to validate the sample group representation. $\mathrm{P}<0.05$ was considered as statistically significance. Chi-square tests or Fisher's exact test for categorical variables and one-way analysis of variance (ANOVA) for continuous variables. The odds ratio (OR) with a $95 \%$ confidence interval $(\mathrm{Cl})$ was estimated by logistic regression analysis. A receiver operating characteristic curve (ROC) was used to assess the sensitivity and specificity of Fol and vitamin B12 in predicting HHcy.

\section{Results}

\subsection{General characteristics}

In total, 800 consecutive patients were enrolled in the study. 403 male (50.38\%) had Hcy level of $14.85 \pm$ $13.70 \mathrm{umol} / \mathrm{L}$ and 397 female (49.62\%) got Hcy level of $10.62 \pm 8.80 \mathrm{umol} / \mathrm{L}, \mathrm{F}=27.175, \mathrm{P}<0.05$ (Table1). Furthermore, of the 800 subjects, Hcy values were $<15 \mathrm{umol} / \mathrm{L}$ in 657 people, and $\geq 15 \mathrm{umol} / \mathrm{L}$ in 143 people, which accounted for $17.88 \%$ (143/800). Age distributions were detected in this study (Table2). Indicated that among 800 people, the proportion of people aged 10 to 18 was not the highest $(27.63 \%)$, however, the number of people in HHcy group was the highest (42.66\%). 


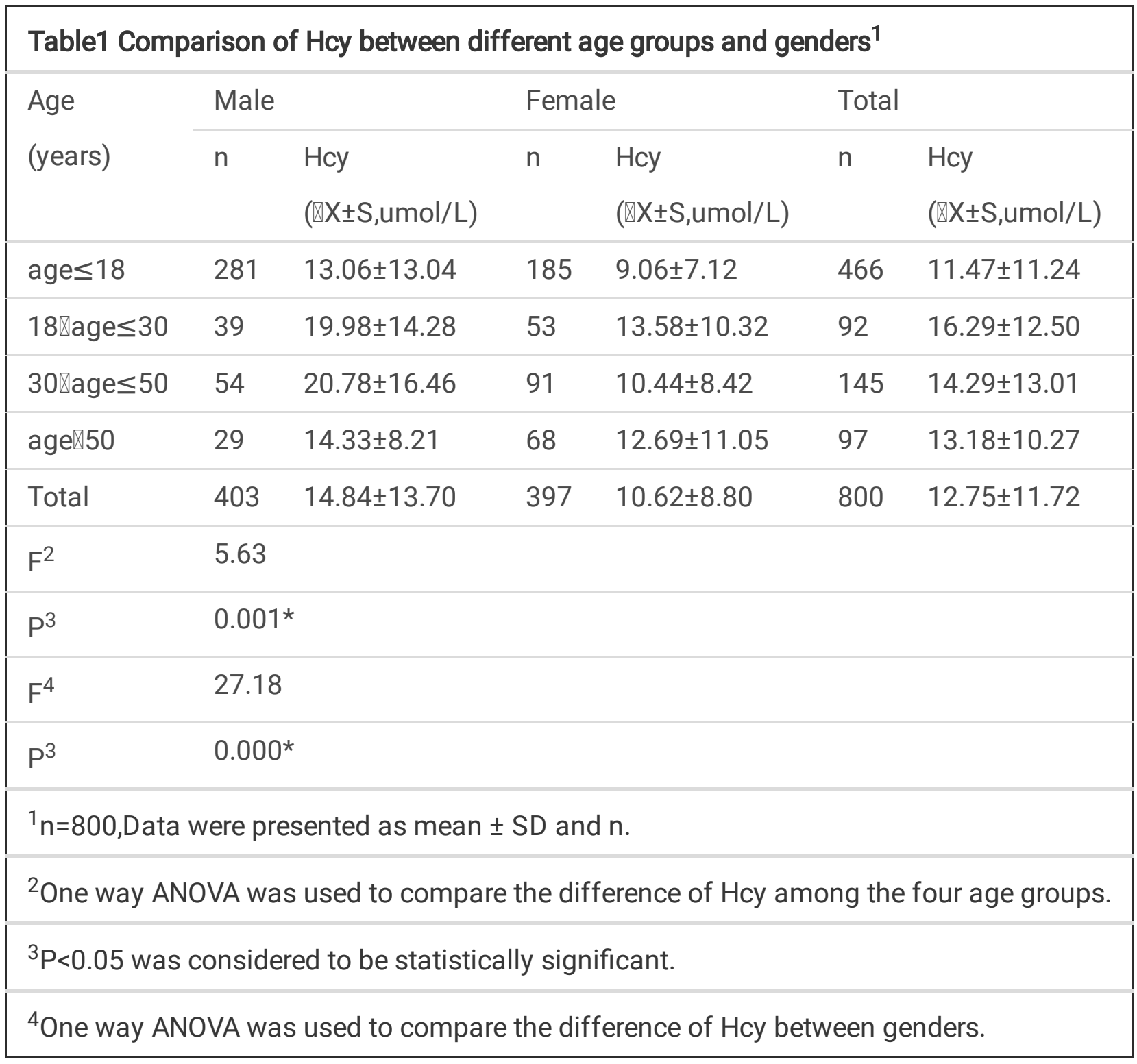

\begin{tabular}{|c|c|c|c|c|c|}
\hline Age & Normal Hcy & HHcy & Total & proportion ${ }^{2}$ & proportion ${ }^{3}$ \\
\hline $0 \otimes A g e \leq 10$ & 241 & 4 & 245 & $30.63 \%$ & $2.80 \%$ \\
\hline $10 \vee$ Age $\leq 18$ & 160 & 61 & 221 & $27.63 \%$ & $42.66 \%$ \\
\hline $18 \varangle$ Age $\leq 30$ & 60 & 32 & 92 & $11.50 \%$ & $22.38 \%$ \\
\hline 30 هAge $\leq 50$ & 114 & 31 & 145 & $18.13 \%$ & $21.68 \%$ \\
\hline Age $₫ 50$ & 82 & 15 & 97 & $12.13 \%$ & $10.49 \%$ \\
\hline Total & 657 & 143 & 800 & $100.00 \%$ & $100.00 \%$ \\
\hline
\end{tabular}

${ }^{2}$ The proportion of this age group in the total of 800 people. 
${ }^{3}$ The proportion of this age group in HHcy group.

\subsection{Comparison of micronutrients between normal Hcy and HHcy group}

Considering the effect of age on micronutrients levels, the comparison were made by age stratification (Table3). The levels of $\mathrm{Fe}, \mathrm{Pb}, \mathrm{Cu}, \mathrm{Ca}, \mathrm{Mg}$, had no significant difference between two groups $(\mathrm{P}>0.05)$. Whereas compared with the normal Hcy people, there were a higher levels of $Z n$, Uric, VA $(P<0.05)$ and a lower level of 25-OH-D3, VB12, Fol, Phos, Alkp $(P<0.05)$ in HHcy group of age $\leq 18$ years old. HHcy group also had a higher level of Zn, Uric, VA $(P<0.05)$ and a lower level of VB12, Fol $(P<0.05)$ in $18<$ age $\leq 30$ years old. Furthermore, a higher levels of $Z n$, Uric, VA, Phos $(P<0.05)$ and a lower levels of VB12, Fol $(P<$ 0.05 ) were found in HHcy group with age $>30$ years old, suggested that HHcy did affect the levels of some micronutrients, or vice versa. 
Table3 Comparison of micronutrients between Normal Hcy and HHcy group ${ }^{1}$

\begin{tabular}{|c|c|c|c|c|c|}
\hline Age & Variable & $\begin{array}{l}\text { Normal Hcy group } \\
(X \pm S)\end{array}$ & $\begin{array}{l}\text { HHcy group } \\
(X \pm S)\end{array}$ & T value & $P$ value ${ }^{2}$ \\
\hline \multirow[t]{13}{*}{$A^{3}$} & 25-OH-D3(ng/ml) & $25.53 \pm 11.98$ & $18.84 \pm 10.96$ & 4.224 & $0.000 *$ \\
\hline & zn(umol/L) & $76.30 \pm 12.39$ & $89.41 \pm 11.60$ & -7.980 & $0.000 *$ \\
\hline & VB12(pg/ml) & $579.32 \pm 296.77$ & $260.48 \pm 121.75$ & 15.069 & $0.000 *$ \\
\hline & Fol(ng/ml) & $11.46 \pm 6.99$ & $4.85 \pm 1.55$ & 7.409 & $0.000 *$ \\
\hline & $\mathrm{Fe}($ umol/L) & $15.70 \pm 5.81$ & $17.16 \pm 6.74$ & -1.841 & 0.066 \\
\hline & $\mathrm{Pb}(\mathrm{ug} / \mathrm{L})$ & $21.88 \pm 6.80$ & $23.35 \pm 8.28$ & -1.568 & 0.118 \\
\hline & $\mathrm{Cu}(\mathrm{umol} / \mathrm{L})$ & $15.08 \pm 2.63$ & $14.65 \pm 3.06$ & 1.172 & 0.242 \\
\hline & $\mathrm{Ca}(\mathrm{mmol} / \mathrm{L})$ & $2.36 \pm 0.09$ & $2.35 \pm 0.10$ & 0.446 & 0.656 \\
\hline & Phos(mmol/L) & $1.58 \pm 0.19$ & $1.38 \pm 0.21$ & 7.460 & $0.000 *$ \\
\hline & $\mathrm{Mg}(\mathrm{mmol} / \mathrm{L})$ & $0.92 \pm 0.06$ & $0.93 \pm 0.07$ & -1.101 & 0.272 \\
\hline & Alkp(U/L) & $228.30 \pm 78.78$ & $154.65 \pm 75.83$ & 7.028 & $0.000 *$ \\
\hline & VA(ng/ml) & $328.06 \pm 56.77$ & $636.00 \pm 64.42$ & -39.784 & $0.000 *$ \\
\hline & Uric(umol/L) & $351.21 \pm 48.52$ & $495.69 \pm 68.504$ & -20.885 & $0.000 *$ \\
\hline \multirow[t]{10}{*}{$B^{4}$} & 25-OH-D3(ng/ml) & $17.62 \pm 9.69$ & $16.23 \pm 7.23$ & 0.709 & 0.480 \\
\hline & zn(umol/L) & $90.10 \pm 11.22$ & $96.53 \pm 10.25$ & -2.694 & 0.008 \\
\hline & VB12(pg/ml) & $430.1 \pm 173.76$ & $301.43 \pm 208.89$ & 3.161 & $0.002^{*}$ \\
\hline & Fol(ng/ml) & $10.31 \pm 4.60$ & $5.99 \pm 1.99$ & 6.255 & $0.000 *$ \\
\hline & $\mathrm{Fe}(\mathrm{umol} / \mathrm{L})$ & $19.21 \pm 7.16$ & $19.57 \pm 6.88$ & -0.233 & 0.817 \\
\hline & $\mathrm{Pb}(\mathrm{ug} / \mathrm{L})$ & $25.45 \pm 7.22$ & $23.64 \pm 5.17$ & 1.255 & 0.213 \\
\hline & $\mathrm{Cu}(\mathrm{umol} / \mathrm{L})$ & $14.92 \pm 3.13$ & $14.34 \pm 4.21$ & 0.743 & 0.459 \\
\hline & $\mathrm{Ca}(\mathrm{mmol} / \mathrm{L})$ & $2.29 \pm 0.08$ & $2.32 \pm 0.10$ & -1.664 & 0.100 \\
\hline & Phos(mmol/L) & $1.14 \pm 0.12$ & $1.13 \pm 0.12$ & 0.601 & 0.549 \\
\hline & $\mathrm{Mg}(\mathrm{mmol} / \mathrm{L})$ & $0.92 \pm 0.06$ & $0.93 \pm 0.06$ & -0.867 & 0.388 \\
\hline
\end{tabular}

${ }^{1}$ Data were presented as mean \pm SD. Considering the influence of age on micronutrients, $T$ - test was carried out according to age stratified. All statistical test was two-sided.

${ }^{2} \mathrm{P}<0.05$ was considered to be statistically significant.

${ }^{3} \mathrm{~A}:$ age $\leq 18$ years, ${ }^{4} \mathrm{~B}: 18<$ age $\leq 30$ years, ${ }^{5} \mathrm{C}:$ age $>30$ years 
Table3 Comparison of micronutrients between Normal Hcy and HHcy group ${ }^{1}$

\begin{tabular}{|c|c|c|c|c|c|}
\hline & Alkp(U/L) & $61.47 \pm 16.05$ & $37.13 \pm 17.77$ & -1.551 & 0.124 \\
\hline & VA(ng/ml) & $442.99 \pm 78.62$ & $665.57 \pm 50.94$ & -14.457 & $0.000 *$ \\
\hline & Uric(umol/L) & $406.22 \pm 74.633$ & $489.28 \pm 121.877$ & -4.052 & $0.000 *$ \\
\hline$c^{5}$ & 25-OH-D3(ng/ml) & $21.74 \pm 9.92$ & $20.61 \pm 7.71$ & 0.723 & 0.471 \\
\hline & zn(umol/L) & $90.36 \pm 13.17$ & $95.51 \pm 11.81$ & -2.429 & $0.016 *$ \\
\hline & VB12(pg/ml) & $467.16 \pm 212.85$ & $240.13 \pm 139.66$ & 6.889 & $0.000 *$ \\
\hline & Fol(ng/ml) & $12.12 \pm 5.16$ & $7.96 \pm 4.24$ & 5.082 & 0.000 * \\
\hline & Fe(umol/L) & $16.19 \pm 5.34$ & $17.22 \pm 4.57$ & -1.214 & 0.226 \\
\hline & $\mathrm{Pb}(\mathrm{ug} / \mathrm{L})$ & $29.88 \pm 8.17$ & $29.62 \pm 7.36$ & 0.202 & 0.840 \\
\hline & $\mathrm{Cu}(\mathrm{umol} / \mathrm{L})$ & $15.01 \pm 2.45$ & $14.77 \pm 3.48$ & 0.548 & 0.584 \\
\hline & $\mathrm{Ca}(\mathrm{mmol} / \mathrm{L})$ & $2.27 \pm 0.09$ & $2.25 \pm 0.12$ & 1.393 & 0.165 \\
\hline & Phos(mmol/L) & $1.10 \pm 0.13$ & $1.22 \pm 0.19$ & -4.778 & $0.000 *$ \\
\hline & $\mathrm{Mg}(\mathrm{mmol} / \mathrm{L})$ & $0.96 \pm 0.06$ & $0.96 \pm 0.06$ & -0.264 & 0.792 \\
\hline & $\operatorname{Alkp}(\mathrm{U} / \mathrm{L})$ & $71.26 \pm 21.38$ & $75.48 \pm 19.78$ & -1.216 & 0.225 \\
\hline & VA(ng/ml) & $542.33 \pm 77.02$ & $887.84 \pm 94.78$ & -26.150 & $0.000 *$ \\
\hline & Uric(umol/L) & $354.10 \pm 86.136$ & $439.28 \pm 115.403$ & -5.631 & $0.000 *$ \\
\hline
\end{tabular}

${ }^{1}$ Data were presented as mean \pm SD. Considering the influence of age on micronutrients, $T$ - test was carried out according to age stratified. All statistical test was two-sided.

${ }^{2} \mathrm{P}<0.05$ was considered to be statistically significant.

${ }^{3} \mathrm{~A}:$ age $\leq 18$ years, ${ }^{4} \mathrm{~B}: 18<$ age $\leq 30$ years, ${ }^{5} \mathrm{C}:$ age $>30$ years

\subsection{Lifestyle differences between Normal Hcy and HHcy group}

87 questionnaire were analyzed (Table4), including 46 people with Hcy< $15 \mathrm{umol} / \mathrm{L}$ as normal Hcy group and 41 people with $\mathrm{Hcy} \geq 15 \mathrm{umol} / \mathrm{L}$ as HHcy group. The ages of the normal Hcy group and the HHcy group were not statistically significant with $29.56 \pm 19.15$ and $25.85 \pm 11.61$, respectively $(P=0.273)$. However, there was a gender difference with more males than females in HHcy group compared to normal group $(P=0.002 ; O R=$ $3.986 ; 95 \% \mathrm{Cl}, 1.633$-9.671). The parameters of nonstatistically significant items were not shown in the table, and the $\mathrm{P}$ value was described in the footnotes. Results suggested that lifestyle or eating habits did affect Hcy levels. 
Table4 Lifestyle differences between Normal Hcy and HHcy group ${ }^{1}$

\begin{tabular}{|c|c|c|c|c|c|c|c|c|}
\hline \multicolumn{2}{|l|}{ Variable } & \multirow{2}{*}{$\begin{array}{l}\text { Normal Hcy } \\
(n=46) \\
29.56 \pm 19.15\end{array}$} & \multirow{2}{*}{$\begin{array}{l}\text { HHcy } \\
(n=41) \\
25.85 \pm 11.61\end{array}$} & \multirow{2}{*}{$\begin{array}{l}x^{2} / t \\
1.10\end{array}$} & \multirow{2}{*}{$\begin{array}{l}P \\
\text { value }^{2} \\
0.273\end{array}$} & \multirow{2}{*}{$\begin{array}{l}\mathrm{OR}^{3} \\
--\end{array}$} & \multicolumn{2}{|c|}{$\begin{array}{l}\text { OR's 95\%Cl } \\
\text { lower upper }\end{array}$} \\
\hline Age & years & & & & & & -- & -- \\
\hline \multirow{2}{*}{$\begin{array}{l}\text { Facing the } \\
\text { entrance } \\
\text { examination }\end{array}$} & yes(\%) & $8(23.5 \%)$ & $15(28.3 \%)$ & \multirow[t]{2}{*}{19.29} & \multirow[t]{2}{*}{$0.000 *$} & \multirow[t]{2}{*}{8.23} & \multirow[t]{2}{*}{3.05} & \multirow[t]{2}{*}{22.21} \\
\hline & no(\%) & $38(76.5 \%)$ & $26(71.7 \%)$ & & & & & \\
\hline \multirow{2}{*}{$\begin{array}{l}\text { The habit of } \\
\text { drinking tea }\end{array}$} & yes(\%) & 42(91.3\%) & $7(17.1 \%)$ & \multirow[t]{2}{*}{48.56} & \multirow[t]{2}{*}{$0.000 *$} & \multirow[t]{2}{*}{0.02} & \multirow[t]{2}{*}{0.01} & \multirow[t]{2}{*}{0.07} \\
\hline & no(\%) & $4(8.7 \%)$ & $34(82.9 \%)$ & & & & & \\
\hline \multirow{2}{*}{$\begin{array}{l}\text { The habit of } \\
\text { drinking } \\
\text { coffee }\end{array}$} & yes(\%) & $40(87 \%)$ & $12(29.3 \%)$ & \multirow[t]{2}{*}{30.00} & \multirow[t]{2}{*}{$0.000 *$} & \multirow[t]{2}{*}{0.06} & \multirow[t]{2}{*}{0.02} & \multirow[t]{2}{*}{0.19} \\
\hline & no(\%) & $6(13 \%)$ & $29(70.7 \%)$ & & & & & \\
\hline \multirow{2}{*}{$\begin{array}{l}\text { The habit of } \\
\text { drinking soda }\end{array}$} & yes(\%) & $40(87 \%)$ & 16(39\%) & \multirow[t]{2}{*}{27.71} & \multirow[t]{2}{*}{$0.000 *$} & \multirow[t]{2}{*}{0.10} & \multirow[t]{2}{*}{0.03} & \multirow[t]{2}{*}{0.28} \\
\hline & no(\%) & $6(13 \%)$ & $25(61 \%)$ & & & & & \\
\hline \multirow{4}{*}{$\begin{array}{l}\text { Intake of } \\
\text { fruits and } \\
\text { vegetables }\end{array}$} & Seldom(\%) & $0(0 \%)$ & $5(12.2 \%)$ & \multirow[t]{4}{*}{711.00} & \multirow[t]{4}{*}{$0.038^{*}$} & -- & -- & -- \\
\hline & Little(\%) & $12(26.1 \%)$ & $11(26.8 \%)$ & & & & & \\
\hline & Often(\%) & $14(30.4 \%)$ & $15(36.6 \%)$ & & & & & \\
\hline & Always(\%) & $20(43.5 \%)$ & $10(24.4 \%)$ & & & & & \\
\hline Vitamin B & yes(\%) & $19(41.3 \%)$ & $4(9.8 \%)$ & 22.68 & $0.000 *$ & 0.08 & 0.02 & 0.25 \\
\hline & no(\%) & $27(58.7 \%)$ & $37(90.2 \%)$ & & & & & \\
\hline $\begin{array}{l}\text { Other } \\
\text { nutrients }\end{array}$ & yes(\%) & $30(65.2 \%)$ & $12(29.3 \%)$ & 11.22 & $0.001 *$ & 0.22 & 0.09 & 0.55 \\
\hline supplements ${ }^{5}$ & no(\%) & $16(34.8 \%)$ & $29(70.7 \%)$ & & & & & \\
\hline Staying up & yes(\%) & $5(10.9 \%)$ & $14(34.1 \%)$ & 6.88 & $0.009 *$ & 4.25 & 1.37 & 13.17 \\
\hline & no(\%) & $41(89.1 \%)$ & $27(65.9 \%)$ & & & & & \\
\hline Anxiety & yes(\%) & $6(13 \%)$ & 13(31.7\%) & 4.42 & $0.035^{\star}$ & 3.10 & 1.05 & 9.13 \\
\hline & no(\%) & $40(87 \%)$ & $28(68.3 \%)$ & & & & & \\
\hline
\end{tabular}

${ }^{1}$ Data were presented as $n(\%)$. The questionnaire included basic information, eating habits, exercise frequency, emotion, family history of disease et al. Non statistically significant factors included National $(P=0.276)$, Smoke $(P=0.097)$, Co-habitant smoke $(P=0.843)$, Drinking $(P=0.598)$, Intake of meat $(P=$ $0.454)$, Intake of soy products $(P=0.072)$, Exercise frequency $(P=0.277)$, Isomnia $(P=0.421)$, Dizyy $(P=$ $0.278)$, Confusion $(P=0.917)$, Depression $(P=0.847)$, Restlessness $(P=0.272)$, Family history of cancer $(P=0.189)$, Family history of hypertension and cardio-cerebrovascular disorders $(P=0.829)$.

${ }^{2} \mathrm{P}<0.05$ was considered to be statistically significant. For more intuitive display purposes, all factors of statistical significant were highlighted. 
Table4 Lifestyle differences between Normal Hcy and HHcy group ${ }^{1}$

${ }^{3}$ Odds Ratio, OR.

${ }^{4}$ Mann - Whitney - U test. Little means $500 \mathrm{~g} /$ week, Often means 500-1500g/week, Always means more than $1500 \mathrm{~g} /$ week.

${ }^{5}$ Other nutrients supplements included vitamin D, vitamin C, selenium (Se) et al.

3.4. The distribution of the MTHFR and MTRR genes of genotypes was compared in normal Hcy and HHcy group

203 people were randomly selected to check the two gene polymorphisms of three sites (Table5), enrolling 68 HHcy patients and 135 people with normal Hcy. The results of Hardy -weinberg tests were $P>0.05$. Numbers of homozygous mutation (TT) in MTHFR C677T were significantly higher in HHcy group compared to normal group $\left(X^{2}=20.99, P=0.000\right)$, nevertheless no significant difference in MTHFR A1298C and MTRR A66G $\left(X^{2}=\right.$ $5.20, P=0.074, \chi^{2}=0.33, P=0.850$ ). Meanwhile, Hcy levels got significant higher in the group of homozygous mutant of MTHFR 677TT than that in MTHFR 677CC and MTHFR 677CT group $(P=0.000)$. However, there were no significant differences of Hcy levels in wild, heterozygous and homozygous mutation of MTHFR A1298C and MTRR A66G $(P=0.196, P=0.526)$ indicated that Hcy levels did affected by gene polymorphism of MTHFR C677T, instead of MTHFR A1298C and MTRR A66G. 


\begin{tabular}{|c|c|c|c|c|c|c|c|c|}
\hline \multirow[t]{2}{*}{ Genotype } & \multirow[t]{2}{*}{$n$} & \multicolumn{2}{|l|}{ numbers(\%) } & \multirow[t]{2}{*}{$x_{x^{2}}$} & \multirow{2}{*}{$\begin{array}{l}P \\
\text { value }^{2}\end{array}$} & \multirow{2}{*}{$\begin{array}{l}\operatorname{Hcy}(\mathbb{X X \pm S}) \\
\text { (umol/L) }\end{array}$} & \multirow[t]{2}{*}{ F value } & \multirow{2}{*}{$\begin{array}{l}\mathrm{P} \\
\text { value }^{2}\end{array}$} \\
\hline & & Normal Hcy & HHcy & & & & & \\
\hline $677 C^{3}$ & 33 & $28(85 \%)$ & $5(15 \%)$ & \multirow[t]{3}{*}{20.99} & \multirow[t]{3}{*}{$0.000^{*}$} & $11.40 \pm 7.39$ & \multirow[t]{3}{*}{18.61} & \multirow[t]{3}{*}{$0.000 *$} \\
\hline $677 \mathrm{CT}^{3}$ & 105 & $77(73 \%)$ & $28(27 \%)$ & & & $14.22 \pm 11.39$ & & \\
\hline $677 \mathrm{TT}^{3}$ & 65 & $29(46 \%)$ & $36(54 \%)$ & & & $28.01 \pm 23.54$ & & \\
\hline $1298 A^{3}$ & 151 & $93(62 \%)$ & $58(38 \%)$ & \multirow[t]{3}{*}{5.20} & \multirow[t]{3}{*}{0.074} & $19.46 \pm 18.17$ & \multirow[t]{3}{*}{1.64} & \multirow[t]{3}{*}{0.196} \\
\hline $1298 A C^{3}$ & 46 & $36(78 \%)$ & $10(22 \%)$ & & & $14.54 \pm 14.47$ & & \\
\hline $1298 \mathrm{CC}^{3}$ & 6 & $5(83 \%)$ & $1(17 \%)$ & & & $13.74 \pm 6.38$ & & \\
\hline
\end{tabular}

\begin{tabular}{|c|c|c|c|c|c|c|c|}
\hline $66 \mathrm{AA}^{4}$ & 105 & $69(66 \%)$ & $36(34 \%)$ & 0.33 & 0.850 & $17.00 \pm 14.56$ & 0.64 \\
\hline $66 \mathrm{AG}^{4}$ & 83 & $56(67 \%)$ & $27(33 \%)$ & & & $19.03 \pm 20.36$ & \\
\hline $66 \mathrm{GG}^{4}$ & 15 & $9(60 \%)$ & $6(40 \%)$ & & & $21.64 \pm 16.42$ & \\
\hline
\end{tabular}

${ }^{1} n=203$,Data were presented as $n(\%)$. MTHFR C677T, MTHFR A1298C and MTRR A66G gene polymorphisms were detected in 203 people.

${ }^{2} \mathrm{P}<0.05$ was considered to be statistically significant.

${ }^{3}$ MTHFR 677CC, CT,TT and MTHFR 1298AA, AC, CC

${ }^{4} \mathrm{MTRR} 66 \mathrm{AA}, \mathrm{AG}, \mathrm{GG}$

\subsection{Logistic regression analysis}

Firstly, a total of 16 factors were statistically $(P<0.05)$ by Logistic univariate regression analyze. That's including Age, Gender, 25-OH-D3, Zn, VB12, Fol, Phos, Alkp, Uric, VA, MTHFR C677T, MTHFR A1298C. Secondly, the multivariate logistic regression (Table6) significantly predicted HHcy development containing higher level of $\mathrm{Zn}(\operatorname{Exp}(B)=1.042 ; 95 \% \mathrm{Cl}, 1.000-1.086, \mathrm{P}=0.050)$, higher Uric $(\operatorname{Exp}(\mathrm{B})=1.014 ; 95 \% \mathrm{Cl}, 1.008$ - 1.019, $P=0.000)$, lower $B 12(\operatorname{Exp}(B)=0.993 ; 95 \% C l, 0.989-0.997, P=0.000)$, lower Fol $(\operatorname{Exp}(B)=0.772 ; 95 \%$ 
$\mathrm{Cl}, 0.657-0.907, \mathrm{P}=0.002)$, and polymorphism of MTHFR C677T $(\operatorname{Exp}(\mathrm{B})=2.923 ; 95 \% \mathrm{Cl}, 1.399-6.107, \mathrm{P}=$ $0.000)$.

\begin{tabular}{|c|c|c|c|c|c|c|}
\hline \multirow[t]{2}{*}{ Variable } & \multirow[t]{2}{*}{$\mathrm{B}^{2}$} & \multirow[t]{2}{*}{ S.E } & \multirow[t]{2}{*}{$\mathrm{Sig}^{3}$} & \multirow[t]{2}{*}{$\operatorname{Exp}(B)^{4}$} & \multicolumn{2}{|c|}{$\operatorname{Exp}(B) 95 \% \mathrm{Cl}^{5}$} \\
\hline & & & & & Lower & Upper \\
\hline $\mathrm{Zn}$ & 0.041 & 0.021 & 0.050 & 1.042 & 1.000 & 1.086 \\
\hline Uric & 0.013 & 0.003 & 0.000 & 1.014 & 1.008 & 1.019 \\
\hline B12 & -0.007 & 0.002 & 0.000 & 0.993 & 0.989 & 0.997 \\
\hline Fol & -0.259 & 0.082 & 0.002 & 0.772 & 0.657 & 0.907 \\
\hline MTHFR C677T & 1.073 & 0.376 & 0.004 & 2.923 & 1.399 & 6.107 \\
\hline Constant & -8.148 & 2.312 & 0.000 & 0.000 & -- & -- \\
\hline
\end{tabular}

${ }^{1}$ Multivariate regression analysis incorporated all significant single factors, converted variables, and used stepwise binary logistic regression to obtain the optimal equation.

${ }^{2}$ Partial regression coefficient.

${ }^{3} \mathrm{sig}, \mathrm{P}<0.05$ was considered to be statistically significant.

${ }^{4}$ Odds Ratio, OR.

${ }^{5}$ OR's $95 \%$ confidence interval.

\subsection{A receiver operating characteristic curve (ROC)}

To predict HHcy levels, the areas under the curve (AUC) obtained 0.829 for Fol and 0.841 for vitamin B12 were optimum sensitivity and specificity respectively by ROC curve analysis (Figure3A.B.C). With the maximum value of Yoden index of 0.521 and Fol concentration of $7.27 \mathrm{ng} / \mathrm{mL}$, the sensitivity and specificity of HHcy were 0.728 and 0.794 , respectively. With the maximum value of Yoden index of 0.529 and VB12 concentration of $256.5 \mathrm{pg} / \mathrm{ml}$, the sensitivity and specificity of HHcy were 0.901 and 0.618 , respectively. In other words, predicted Hcy level may be higher than $15 \mathrm{umol} / \mathrm{L}$ by ROC curve analyzed on Fol below 7.27 $\mathrm{ng} / \mathrm{mL}$ and/or vitamin B12 below $256.5 \mathrm{pg} / \mathrm{mL}$.

\section{Discussion}

Similar to previous studies, there were more male than female in HHcy group. However, different from previous studies $(29 ; 30)$ on the age distribution (shown in Table 2), a specific age group was identified who, although young, had a greater likelihood to develop HHcy without awareness. The reason why the Hcy levels of 18-30-year-old were higher than other groups may be that the lifestyle of young people was not healthy. On the contrary, the elderly pay more attention to their own health and often go to the nutrition department for 
nutrition consultation, indicated that the levels of plasma Hcy were influenced not only by environmental and genetic factors, but also by nutrition and lifestyle.

HHcy occurs not only in a variety of cancers, osteoporosis, neuropsychiatric disorders, and cerebrovascular diseases, but also quietly in healthy young people without major illnesses. In this study, healthy people without major diseases and disorders and with discomfort, occasional dizziness and confusion were enrolled as the research objects to carry out the nutritional examination, of which 61 children aged 10 - 18 accounted for $42.66 \%$ (shown in Table 2) with the average Hcy levels above $15 \mathrm{umol} / \mathrm{L}$, which were significantly higher than Helena Caldeira-Araújo's results ${ }^{(31)}$ about a cohort of 9-year-old and 17-year-old healthy children with plasma tHcy $(\mu \mathrm{M})$ concentrations of $3.8 \pm 1.8$ and $8.7 \pm 3.4$, respectively (shown in Table 1 ). One of the possible reasons might be that their subjects followed the recommended dose/age and vegetables/fruit intake in the Mediterranean diet, while our subjects located in the Northeast of China, where the climate is relatively cold and lack of sunlight and seasonal vegetables. People's diet was mainly dominated by meat and salt and the intake of vegetables and fruit were far from enough. Therefore, compared with this European study, our results showed a clear trend of low age accompanied by high Hcy, which was what this study wants to highlight.

Micronutrients and vitamins play a basic role in regulating the metabolism of Hcy as cofactors of enzyme. We found that the level of vitamin D was significantly lower in the HHcy group under 18 years old than that in normal Hcy group in this study (shown in Table 3). Arif Malik's study ${ }^{(32)}$ have shown that decreased vitamin D level can inhibit CBS activity, which led to a negative effect on Hcy and Sam balance eventually leading to HHcy, suggested the possible cause of our results. Nahla Al-Bayyari's study (33) also substantiated that vitamin D3 intervention with a treatment dose of $50000 \mathrm{IU}$ per week for at least 2 months can help decrease $\mathrm{BMI}$ and $\mathrm{Hcy}$ level. Therefore, to prevent the occurrence of HHcy related chronic diseases, it is important to check and supply vitamin D to correct Hcy level in blood from childhood.

In our results, we found that vitamin A, Uric and Zn had higher levels in HHcy group, and there were statistical differences in all ages (shown in Table 3). It was hard to determine the causal relationship, since this was a cross-sectional study. These factors may be accompanied by the HHcy, may be the cause of the HHcy and may also be the cumulative response. in Dilli Det's ${ }^{\left({ }^{34}\right)}$ mother-infant pairs study enrolled 108 newborns with CHD and 103 healthy newborns, then reported that high Hcy and Zn level with low vitamin D level might be involved In the pathogenesis of CHD. Zn, as an intracellularion, was essential for the activity of many enzymes. Importantly, methionine synthase (MTR) and BHMT are both Zn-dependent methyltransferases, which participate in the remethylation of Hcy ${ }^{(35)}$. Hee-Jin Kim's study ${ }^{(36)}$ revealed that Uric was also positively associated with Hcy through retrospectively analyzed 861 subjects. Thomas Olsen's research (37) showed that plasma Hcy was lower among participates in the lower serum vitamin A levels. Our study also found higher Hcy with higher levels of vitamin A and Uric in all age stratified (shown in Table 3). In our study the reason for the higher $\mathrm{Zn}$ content in HHcy group may be that the diet structure of patients was mainly dominated by the high levels of purine, vitamin $A$ and $Z n$ in meat.

The intake of fruits and vegetables was significantly less in the HHcy group than that in the normal Hcy group (shown in Table 4). Therefore, we recommended a balanced diet, rather than a vegetarian diet. Many 
people thought that having more vegetables and fruits can help reduce the Hcy. Actually, deficiency of vitamin B12 in vegetarians also disturb the metabolism of Hcy. Yi-Chia Huang ${ }^{(38)}$ indicated that the mean plasma concentration of B12 was lower in vegetarians than that in non-vegetarians, which resulted in the increase of plasma Hcy. Increase of VB6 and Fol had little effect on plasma Hcy levels as individuals got adequate VB6 and Fol status. Therefore, a balanced diet is the most important.

Meanwhile, in this study, people with the habits of drinking tea, coffee and soda accounted for a larger proportion in the normal Hcy group, and their Hcy level was lower than those without these habits (shown in Table 4). Paradoxically, in Marina J Grubben's( ${ }^{(39)}$ crossover trial study, the concentrations of Hcy and alanine transaminase in fasting plasma were significantly increased after drinking high dose coffee two weeks, while the concentrations of VB12 or Fol had no significant effect. However, in our study, the subjects were not involved in the high dose issue, so it may be beneficial to maintain the Hcy homeostasis by habitually taking low-dose coffee soda and tea.

Our results showed that the levels of Hcy were 3-5 times higher than the normal range in students who were facing great pressure to prepare for high school and college entrance examination (shown in Table 4). They often sleepless, anxiety, depression and restlessness. The distribution of sleepless with anxiety was also statistically significant in HHcy group compared with the normal Hcy group, indicated that there was a correlation between HHcy and emotional stress led by depression, anxiety and vertigo. Prospective clinical or basic research is needed to further confirm the causality, so as to improve the mental health of adolescents. The same phenomenon was also found in kuo-hsuan Chung's study (40), that the level of serum Hcy was positively correlated with the increase of depression and anxiety in older boys. David J. White's randomized, double-blind, placebo-controlled trial ${ }^{(41)}$ also confirmed that multi-vitamin and mineral (MVM) supplementation for four weeks may have beneficial effects on mood, which was based on the increase of Bvitamins and the decrease of Hcy in healthy young adults.

From the 203 samples in our study, the frequencies of the MTHFR 677T allele and the 677TT genotype were $58 \%$ and $32 \%$, the MTHFR $1298 \mathrm{C}$ allele and the $1298 \mathrm{CC}$ genotype were $13.1 \%$ and $1.4 \%$, the MTRR $66 \mathrm{G}$ allele and the 66GG genotype were $28 \%$ and 7\% (shown in Table 5). Compared to Boyi Yang's ${ }^{29}$ research, the mutation of MTHFR C677T was significantly higher, while MTHFR A1298C was lower in our study, and there was little difference of MTRR A66G between their and our study. It should be noted that the Hcy level in homozygous mutant of MTHFR 1298CC was significantly lower than that in wild type 1298AA (13.74 vs 19.46) (shown in Table 5). Similar to the results of IO Oliveira's study ${ }^{(42)}$, compared with 1298AA group, the Hcy concentration of MTHFR 1298 CC decreased in male - 10\% and in female - $5 \%$ respectively. In addition to us, Bruno Zappacosta's study ${ }^{(43)}$ got the same result that Hcy value was higher in the wild-type (1298 AA), and lower in the homozygote's mutation (1298 CC). Obviously, in our results, although TT polymorphism of MTHFR significantly contributed to the increase of Hcy, there were still many individuals with MTHFR TT in the group with normal Hcy, which should be reflected on the real value of gene detection and the interaction between gene and environment. For the Individuals with gene mutation, we should pay more attention to the supplement of daily diet to match with reasonable nutrition of vitamin B especially at the young age, so as to avoid the high level of Hcy in the blood for several years without known, which may eventually lead to the 
occurrence of disease. Therefore, in order to reduce the incidence of HHcy related diseases, nutritional intervention and lifestyle improvement should be carried out in the early stage of children with gene mutation.

In order to determine the correlation between HHcy and Fol as well as VB12 to predict Hcy $\geq 15 \mathrm{umol} / \mathrm{L}$, we used ROC curve to study the Hcy, Fol and VB12 values in 800 subjects, obtaining the appropriate cut off values of sensitivity and specificity as Fol at $7.27 \mathrm{ng} / \mathrm{ml}$ and vitamin B12 at $256.5 \mathrm{pg} / \mathrm{ml}$ (shown in Figure 3), which may add to a novel method to improve the detection rate of HHcy.

For the first time, this study comprehensively studied the relationship between Hcy and micronutrients in different age groups. In consideration of the fact that there were many persons with $\mathrm{HHcy}$ in the low-age population, we randomly selected part of the subjects to conduct relevant questionnaire survey to determine the correlation with their daily diet and living habits. Meanwhile, we randomly selected part of subjects to complete the relevant genotype test comprehensively to judge the genetic and environmental impact, including those who have no major disease or obvious discomfort symptoms. Although our case-control study had some limitations, our results can still provide valuable clues for future HHcy research and clinical strategy.

\section{Conclusions}

In summary, stress reduction, reasonable diet, adequate sleep and diversified nutrients can remedy the risk of disease caused by polymorphism of Fol related genes. The levels of vitamin D, Zn, Phos, Alkp, Uric, Fol and vitamin B12 should also be noticed in HHcy people.

\section{Declarations}

\subsection{Ethics approval and consent to participate}

This study fulfilled the principles of the Declaration of Helsinki and was approved by the ethics committee at Shengjing Hospital of China Medical University, China. and has been registered with the Trial registration: ISRCTN, ChiCTR1900025136. Registered 13 August 2019, http://www.chictr.org.cn/.URL:http://www.chictr.org.cn/edit.aspx?pid=42154\&htm=4.

\subsection{Consent for publication}

All participants received written informed consent to use their clinical data for research purposes and consent to publication.

\subsection{Availability of data and materials}

The datasets generated during and/or analysed during the current study are not publicly available due patient privacy but are available from the corresponding author on reasonable request.

\subsection{Competing interests}

The authors declare that they have no competing interests" in this section. 


\subsection{Funding}

This research was supported by the National Natural Science Foundation of China, protocol no. (82073545区 81570811); Clinical projects in ShengJing Hospital in 2019 - Clinical study on homocysteine and vitamin/trace elements in blood; the Newly Established Nationwide Medical Experts Committee Funded Program in 2018; ShengJing Hospital 345 Talent Project and CNS-ZD Tizhi and Health Fund, protocol no.CNS-ZD2019059.

\subsection{Authors' contributions}

The authors' responsibilities were as follows-JXY and JK designed the study; JXY and DD collected the subjects; YLZ, NL, WYL, YMP, JQG,YF and HZ assisted conducted the research; YLZ, JXY and DD analyzed data; JXY and YLZ wrote paper. JK had primary responsibility for the final content. All authors read and approved the final manuscript. None of the authors reported a conflict of interest related to the study.

\subsection{Acknowledgements}

Not applicable

\section{References}

1. Alam SF, Kumar S, Ganguly P. Measurement of homocysteine: a historical perspective. Journal of clinical biochemistry nutrition. 2019;65:171-7.

2. Fu Y, Wang $X$, Kong W. (2018) Hyperhomocysteinaemia and vascular injury: advances in mechanisms and drug targets. 175, 1173-1189.

3. Fezeu LK, Ducros V, Guéant JL, et al. MTHFR 677C $\rightarrow$ T genotype modulates the effect of a 5-year supplementation with B-vitamins on homocysteine concentration: The SU.FOL.OM3 randomized controlled trial. PloS one. 2018;13:e0193352.

4. Zaric BL, Obradovic M, Bajic V, et al. Homocysteine and Hyperhomocysteinaemia. Curr Med Chem. 2019;26:2948-61.

5. Liew SC, Gupta ED. Methylenetetrahydrofolate reductase (MTHFR) C677T polymorphism: epidemiology, metabolism and the associated diseases. Eur J Med Genet. 2015;58:1-10.

6. Ventura P, Panini R, Verlato $C$, et al. Hyperhomocysteinemia and related factors in 600 hospitalized elderly subjects. Metab Clin Exp. 2001;50:1466-71.

7. Price BR, Wilcock DM, Weekman EM. Hyperhomocysteinemia as a Risk Factor for Vascular Contributions to Cognitive Impairment and Dementia. Front Aging Neurosci. 2018;10:350.

8. Födinger M, Buchmayer $\mathrm{H}$, Sunder-Plassmann G. Molecular genetics of homocysteine metabolism. Miner Electrolyte Metab. 1999;25:269-78.

9. Locasale JW. Serine, glycine and one-carbon units: cancer metabolism in full circle. Nature reviews Cancer. 2013;13:572-83.

10. Frosst $\mathrm{P}, \mathrm{Blom} \mathrm{HJ}$, Milos $\mathrm{R}$, et al. A candidate genetic risk factor for vascular disease: a common mutation in methylenetetrahydrofolate reductase. Nat Genet. 1995;10:111-3. 
11. Moll S, Varga EA. Homocysteine and MTHFR Mutations. Circulation. 2015;132:e6-9.

12. Zhao P, Hou J, Wu H, et al. Analysis of genetic polymorphism of methylenetetrahydrofolate reductase in a large ethnic Hakka population in southern China. Medicine. 2018;97:e13332.

13. Fong CS, Shyu HY, Shieh JC, et al. Association of MTHFR, MTR, and MTRR polymorphisms with Parkinson's disease among ethnic Chinese in Taiwan. Clin Chim Acta. 2011;412:332-8.

14. Lajin B, Alhaj Sakur A, Michati R, et al. Association between MTHFR C677T and A1298C, and MTRR A66G polymorphisms and susceptibility to schizophrenia in a Syrian study cohort. Asian journal of psychiatry. 2012;5:144-9.

15. Kaya EF, Karakus N, Ulusoy AN, et al. Association of the MTHFR Gene C677T Polymorphism with Breast Cancer in a Turkish Population. Oncology research treatment. 2016;39:534-8.

16. Ramos-Silva A, Figuera LE, Soto-Quintana OM, et al. Association of the C677T polymorphism in the methylenetetrahydrofolate reductase gene with breast cancer in a Mexican population. Genetics molecular research: GMR. 2015;14:4015-26.

17. Couto FD, Adorno EV, Menezes JF, et al. C677T polymorphism of the MTHFR gene and variant hemoglobins: a study in newborns from Salvador, Bahia, Brazil. Cadernos de saude publica. 2004;20:529-33.

18. Beydoun MA, Beydoun HA, Gamaldo AA, et al. Epidemiologic studies of modifiable factors associated with cognition and dementia: systematic review and meta-analysis. BMC Public Health. 2014;14:643.

19. Moretti R, Caruso P. (2019) The Controversial Role of Homocysteine in Neurology: From Labs to Clinical Practice. International journal of molecular sciences 20.

20. Ford TC, Downey LA, Simpson T. The Effect of a High-Dose Vitamin B Multivitamin Supplement on the Relationship between Brain Metabolism and Blood Biomarkers of Oxidative Stress. 10: A Randomized Control Trial; 2018.

21. Smith AD, Refsum H. Homocysteine, B Vitamins, and Cognitive Impairment. Ann Rev Nutr. 2016;36:21139.

22. Scaglione F, Panzavolta G. Folate, folic acid and 5-methyltetrahydrofolate are not the same thing. Xenobiotica. 2014;44:480-8.

23. Al-Bayyari N, Al-Zeidaneen S, Hailat R, et al. Vitamin $\mathrm{D}(3)$ prevents cardiovascular diseases by lowering serum total homocysteine concentrations in overweight reproductive women: A randomized, placebocontrolled clinical trial. Nutrition research. 2018;59:65-71.

24. Wu L, Zhou X, Li T, et al. Improved Sp1 and Betaine Homocysteine-S-Methyltransferase Expression and Homocysteine Clearance Are Involved in the Effects of Zinc on Oxidative Stress in High-Fat-DietPretreated Mice. Biol Trace Elem Res. 2018;184:436-41.

25. Baggott JE, Tamura T. Homocysteine, iron and cardiovascular disease: a hypothesis. Nutrients. 2015;7:1108-18.

26. Józefczuk J, Kasprzycka W, Czarnecki R, et al. Homocysteine as a Diagnostic and Etiopathogenic Factor in Children with Autism Spectrum Disorder. J Med Food. 2017;20:744-9.

27. Dragan S, Buleu F, Christodorescu R, et al. Benefits of multiple micronutrient supplementation in heart failure: A comprehensive review. Critical reviews in food science nutrition. 2019;59:965-81. 
28. Houston M. The role of nutrition and nutraceutical supplements in the treatment of hypertension. World J Cardiol. 2014;6:38-66.

29. Yang B, Liu Y, Li Y, et al. Geographical distribution of MTHFR C677T, A1298C and MTRR A66G gene polymorphisms in China: findings from 15357 adults of Han nationality. PloS one. 2013;8:e57917.

30. Meng H, Li Y, Zhang W, et al. The relationship between cognitive impairment and homocysteine in a B12 and folate deficient population in China: A cross-sectional study. Medicine. 2019;98:e17970.

31. Caldeira-Araujo H, Ramos R, Florindo C, et al. (2019) Homocysteine Metabolism in Children and Adolescents: Influence of Age on Plasma Biomarkers and Correspondent Genotype Interactions. Nutrients 11.

32. Malik A, Saleem S, Basit Ashraf MA, et al. 1, 25-dihydroxyvitamin D3, a potential role player in the development of thyroid disorders in schizophrenics. Pakistan journal of medical sciences. 2016;32:1370-4.

33. Al-Bayyari N, Al-Zeidaneen S, Hailat R, et al. Vitamin D3 prevents cardiovascular diseases by lowering serum total homocysteine concentrations in overweight reproductive women: A randomized, placebocontrolled clinical trial. Nutrition research. 2018;59:65-71.

34. Dilli D, Dogan NN, Orun UA, et al. Maternal and neonatal micronutrient levels in newborns with CHD. Cardiol Young. 2018;28:523-9.

35. Jing M, Rech L, Wu Y, et al. Effects of zinc deficiency and zinc supplementation on homocysteine levels and related enzyme expression in rats. Journal of trace elements in medicine biology: organ of the Society for Minerals Trace Elements. 2015;30:77-82.

36. Kim HJ, Sohn IW, Kim YS, et al. (2020) The Different Relationship between Homocysteine and Uric Acid Levels with Respect to the MTHFR C677T Polymorphism According to Gender in Patients with Cognitive Impairment. Nutrients 12.

37. Olsen T, Vinknes KJ, Svingen GF, et al. The risk association of plasma total homocysteine with acute myocardial infarction is modified by serum vitamin A. European journal of preventive cardiology. 2018;25:1612-20.

38. Huang YC, Chang SJ, Chiu YT, et al. The status of plasma homocysteine and related B-vitamins in healthy young vegetarians and nonvegetarians. Eur J Nutr. 2003;42:84-90.

39. Grubben MJ, Boers GH, Blom HJ, et al. Unfiltered coffee increases plasma homocysteine concentrations in healthy volunteers: a randomized trial. Am J Clin Nutr. 2000;71:480-4.

40. Chung KH, Chiou HY, Chen YH. Associations between serum homocysteine levels and anxiety and depression among children and adolescents in Taiwan. Scientific reports. 2017;7:8330.

41. White D, Cox K, Peters R, et al. Effects of Four-Week Supplementation with a Multi-Vitamin/Mineral Preparation on Mood and Blood Biomarkers in Young Adults: A Randomised, Double-Blind, PlaceboControlled Trial. Nutrients. 2015;7:9005-17.

42. Oliveira IO, Silva LP, Borges MC, et al. Interactions between lifestyle and MTHFR polymorphisms on homocysteine concentrations in young adults belonging to the 1982 Pelotas Birth Cohort. Eur J Clin Nutr. 2017;71:259-66. 

and A1298C polymorphisms: genotype frequency and association with homocysteine and folate levels in middle-southern Italian adults. Cell Biochem Funct. 2014;32:1-4.

\section{Figures}

From June 2019 to December 2019, people who had health examination in the nutrition department were introduced to the trial contents, asked whether they were willing to join the trial, and signed informed consent.

\begin{tabular}{|l|l|l|}
\hline Inclusion criteria. & & $\begin{array}{l}\text { Exclusion criteria } \\
\text { 1. No restrictions on age and gender. }\end{array}$ \\
$\begin{array}{l}\text { 2. No obvious symptoms of discomfort. } \\
\text { 3. Voluntary participation. }\end{array}$ & & $\begin{array}{l}\text { 2.Without independent thinking ability. } \\
\text { 3. Unconscious patients. }\end{array}$ \\
\hline
\end{tabular}

Blood Hcy test was performed

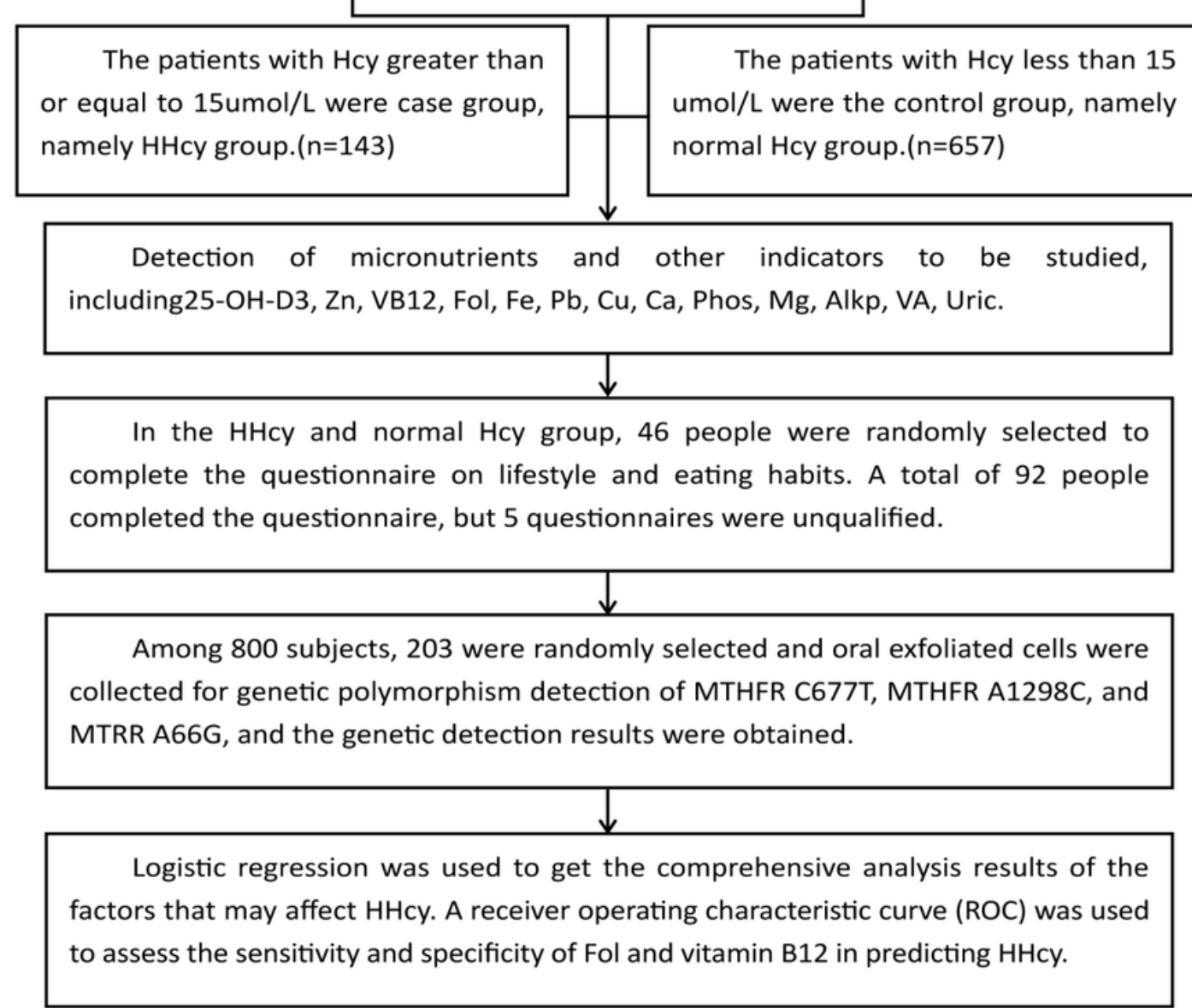

\section{Figure 1}


The route diagram of the experiment.

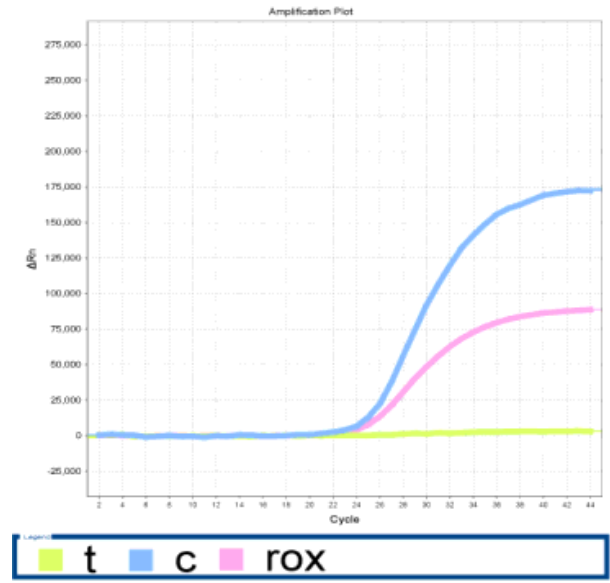

wild-type
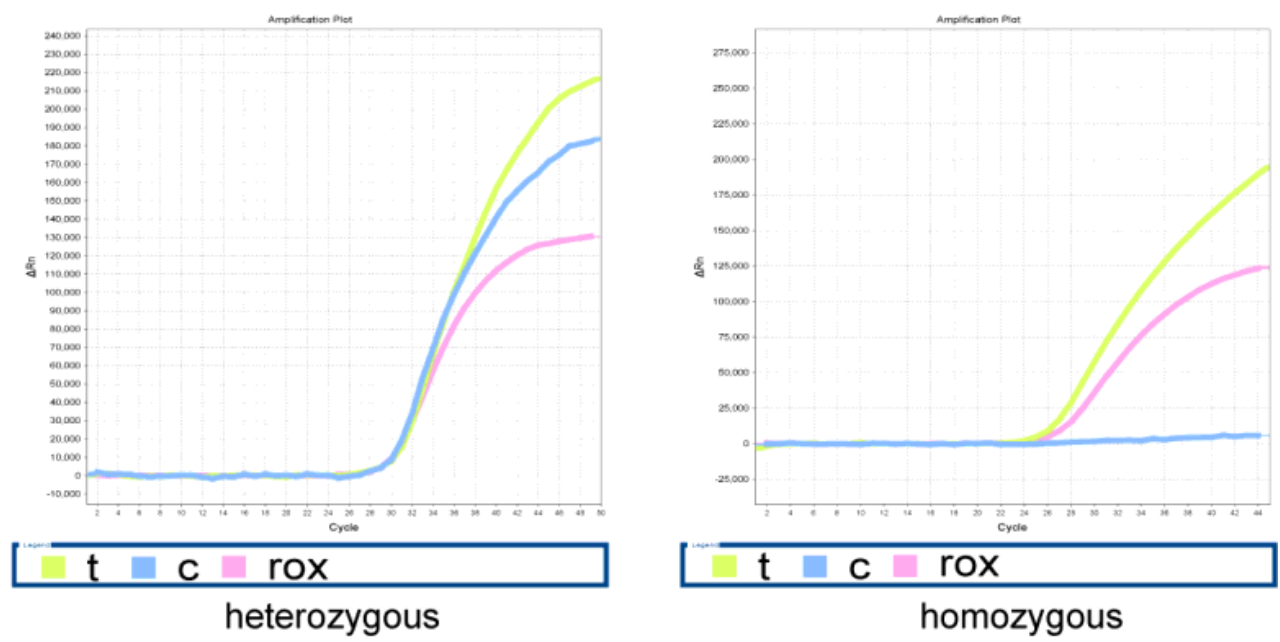

Figure 2

t represented FAM fluorescence channel, c showed VIC fluorescence channel, and rox indicated internal reference. Wild-type included MTHFR 677CC, MTHFR 1298AA and MTRR 66AA. Heterozygous contained MTHFR 677CT, MTHFR 1298AC and MTRR 66AG. Homozygous covered MTHFR 677TT, MTHFR 1298CC and MTRR 66GG.

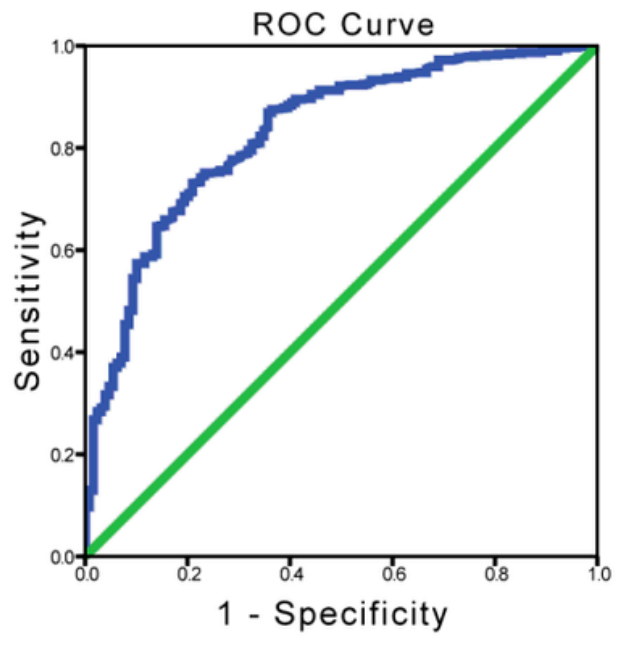

A

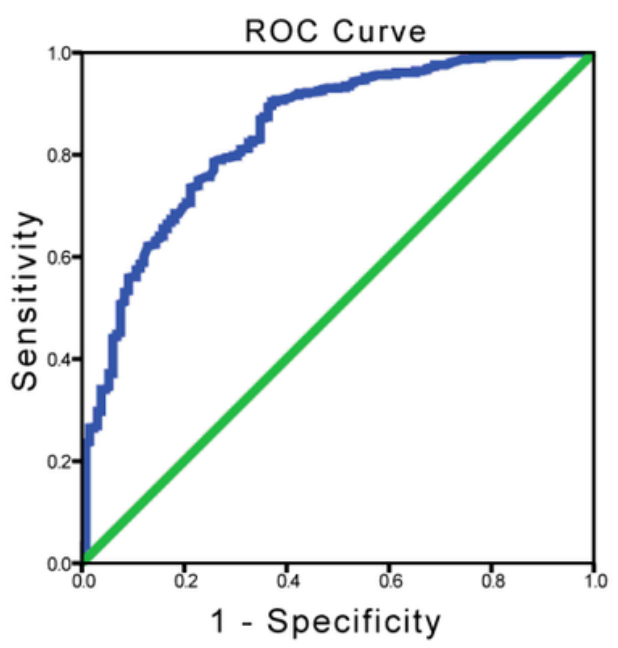

B

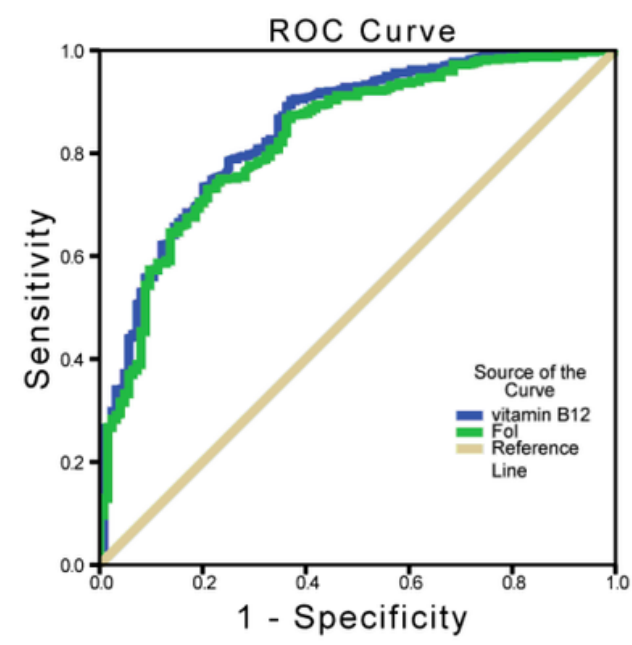

C

\section{Figure 3}

A. ROC curve of folic acid, B. ROC curve of vitamin B12, and C. ROC curve combined folic acid and vitamin B12. ROC curve was used to analyze the Fol and vitamin B12 values of 800 subjects. 